\title{
Cantharis in the early treatment of minor burns
}

\author{
A. M. LEAMAN ${ }^{1} \&$ D. GORMAN ${ }^{2}$ \\ Department of Accident and Emergency, ${ }^{1}$ Royal Liverpool Hospital, Liverpool, and \\ ${ }^{2}$ Warrington General Hospital, Warrington, England
}

\section{SUMMARY}

The analgesic action of the homeopathic preparation Cantharis in the treatment of minor burns was assessed in a series of 34 patients. Under double blind conditions no statistically significant difference was found between Cantharis and a placebo.

\section{INTRODUCTION}

Cantharis is a preparation widely used by homeopathic physicians in the treatment of burns. It is said to relieve pain and accelerate healing. Derived from the dried beetle Cantharis Vesicatoria, Cantharis contains $0.6 \% \mathrm{w} / \mathrm{v}$ cantharidin which is its active principle and the anhydride of cantharidic acid. Cantharidin has been used through the ages to treat various ailments (Sollman, 1957). More recently it has been administered topically in experiments to produce superficial blistering of the skin (Armstrong et al., 1953).

In accordance with their principle of treating like with like, homeopathic physicians treat a blister forming disease (burns) with a blister forming substance (Cantharis). For homeopathic purposes Cantharis is given in greatly diluted form and as such is free from adverse effects.

The aim of this study was to assess the analgesic effects of Cantharis compared with placebo in the early treatment of minor burns. A homeopathic physician advised on the potency of Cantharis to be used, on the form it should be given, and on the frequency of administration.

Cantharis tablets of potency $200 \mathrm{C}$ were recommended for use and these are prepared in the following way.

From the mother solution of Cantharis one part is taken and added to 99 parts of an

Correspondence: $\mathrm{Mr}$ A. M. Leaman, Senior Registrar in Accident and Emergency, Royal Liverpool Hospital, Liverpool, England. 
alcohol/water mixture. This forms a potency of $1 \mathrm{C}$. If one part of this is taken and产 added to 99 parts of the alcohol/water mixture a solution of potency $2 \mathrm{C}$ is obtained. The process is repeated 200 times to obtain a solution of $200 \mathrm{C}$.

Glass flasks are used to hold the solutions and mixing occurs by shaking the flasks by hand. The technique by which the flasks are shaken (succussion) is held by homeopathic physicians to be responsible for potentiating the remedy.

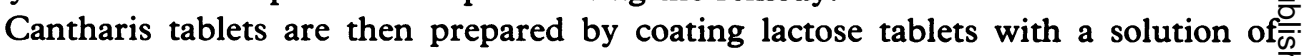
potency $200 \mathrm{C}$.

\section{METHOD}

Patients of 15-60 years with minor burns sustained within the preceeding $6 \mathrm{~h}$ were considered for the study. A minor burn was defined as one which could be safely treatedi్ with dressings alone on an out-patient basis and which involved less than $5 \%$ of the body surface. Patients with burns of the head and neck were excluded.

Informed written consent was obtained from all those who agreed to participate. Patients were asked to record their pain on a horizontal linear analogue scale (from $0-\overbrace{\mathbb{D}}^{\mathbb{D}}$ 10). The burn was then treated in a standard fashion using a paraffin gauze dressing. $\frac{3}{0}$

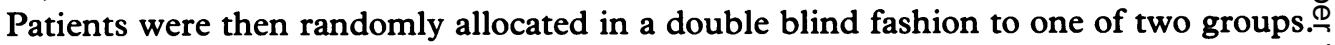

\section{Group 1-Cantharis and paracetamol}

In this group patients were given one gram of paracetamol to swallow and a Cantharis tablet to chew. At hourly intervals for the next $5 \mathrm{~h}$ they recorded their pain on the scale and then chewed a Cantharis tablet. At $6 \mathrm{~h}$ they recorded their pain and were then⿳亠口冋口巾 allowed to use the paracetamol as required.

\section{Group 2-dummy tablet and paracetamol}

This group proceeded exactly as Group 1 except that they used plain lactose tablets instead of those impregnated with Cantharis.

The pain scales were collected in the follow-up clinic. Each patient made seven? recordings on the scales. These were represented on graphs and joined by a line. Theo area under the line was taken as 'pain suffered'.

\section{RESULTS}

There were 17 patients in the Cantharis group and 17 in the control group. Observers? who reviewed the patients at follow-up confirmed that the burns sustained were minoro 
and that those studied formed a reasonably homogenous group within which comparisons could be made.

In the Cantharis group the mean area under the line (that is, 'pain suffered') was 5978 units (SD 4172 units). In the placebo group the mean was 6946 units (SD 3215 units).

The two groups were compared using the Mann-Whitney $U$-test and the unpaired sample $t$-test and no significant difference found.

The average percentage reduction in pain between the first and last recordings was $61 \%$ in the Cantharis group and $66 \%$ in the placebo group.

\section{DISCUSSION}

Apart from some improvement in the type of dressings used there have been very few recent advances in the treatment of minor burns and in view of the current interest in alternative remedies it was thought reasonable to assess the effects of the homeopathic preparation Cantharis in the treatment of these common injuries. This modest but properly controlled trial has failed to show any difference between Cantharis and placebo and gives support to those who believe that the successes of homeopathic medicine are due more to psychology than pharmacology.

\section{REFERENCES}

Sollman T. (1957) In: A Manual of Pharmacology 8th edition, 160. W. B. Saunders, Philadelphia. Armstrong D. (1953) Observations on chemical excitants of cutaneous pain. Fournal of Physiology $120,326$. 